\section{El génesis de la publicidad vernácula}

Javier Enrique Posso Jiménez ${ }^{(1)}$, Carlos Alberto Santacruz Londoño ${ }^{(2)}$ y Andrés Ricardo Novoa Montoya ${ }^{(3)}$

Resumen: Este artículo es producto de la investigación titulada "Publicidad Vernácula, Fase I. Análisis de los medios y modelos de producción publicitaria popular", la cual finalizó en el año 2019 con financiación de la Universidad Jorge Tadeo Lozano. El propósito de este texto es dar cuenta de los puntos de identidad que se construyen en los espacios periféricos de Cartagena de Indias, de aquellas herramientas de comunicación que utilizan los comerciantes, artistas y artesanos para solucionar sus necesidades de difusión y promoción de productos o servicios en las dinámicas de comercialización cotidiana que ejecutan. Para registrar este fenómeno, el semillero de Lenguajes Urbanos se dio a la tarea de realizar un proceso de revisión bibliográfica, documentando los conceptos principales que se abordan en el ejercicio de la producción publicitaria popular-Publicidad Vernácula-, realizó entrevistas a profundidad no estructuradas a académicos y artistas empíricos para ubicar procesos, espacios y medios en donde interviene la publicidad vernácula, participó en los talleres de producción de José Corredor Rodelo "El Runner", empleando técnicas etnográficas, y ejecutó recorridos para documentar cuándo, cómo, dónde y porqué se utiliza este tipo de Publicidad.

Palabras clave: cultura - popular - urbano - vernáculo - publicidad - sociedad - lenguaje - comunicación - diseño e imagen.

[Resúmenes en inglés y portugués en las páginas 217-218]

(1) Profesor tiempo completo Universidad Jorge Tadeo Lozano Bogotá, Escuela de Publicidad; Facultad de Artes y Diseño, Semillero de Investigación: Lenguaje Urbano, javier. posso@utadeo.edu.co

(2) Profesor tiempo completo Universidad Jorge Tadeo Lozano Bogotá, Escuela de Publicidad; Facultad de Artes y Diseño, Semillero de investigación: Lenguaje Urbano, carlos. santacruzl@utadeo.edu.co

(3) Profesor tiempo completo Universidad Jorge Tadeo Lozano Bogotá, Programa de Publicidad; Facultad de Artes y Diseño, Semillero de investigación: Lenguaje Urbano, andres. novoa@utadeo.edu.co 


\section{Introducción}

Para el desarrollo de este proyecto, el problema de investigación se aborda desde una orilla que percibe que los esquemas publicitarios desarrollados por algunas de las agencias alrededor del mundo, se enfocan en la construcción de mensajes globales, es decir que la conceptualización de sus mensajes y el manejo de herramientas de difusión tradicionalmente se edifican alrededor de estereotipos impuestos por la dinámica de consumo y consumismo, guiados por las premisas del sistema capitalista. El proyecto de investigación "Publicidad Vernácula" pretende dar cuenta de los puntos de identidad que se construyen en los espacios periféricos de Cartagena de Indias, es decir aquellas herramientas de comunicación que utilizan los comerciantes, artistas y artesanos para solucionar sus necesidades de difusión y promoción de productos o servicios en las dinámicas de comercialización cotidiana que ejecutan. Específicamente pretende definir y analizar los conceptos, los medios y prácticas de producción publicitaria popular -publicidad vernácula- desde diferentes casos de estudio; descifrando elementos estéticos, culturales e identitarios que permitan revitalizar el ejercicio publicitario. Para ello inicialmente el Semillero se dio a la tarea de definir las características que posee la publicidad vernácula, seleccionó y analizó casos de estudio relacionados con la gráfica popular de la ciudad de Cartagena y los documentó con el objetivo de elaborar una guía ejecucional para el diseño de campañas vernáculas. La metodología implementada correspondió a un proceso de investigación de corte cualitativo en donde se realizó una etnografía desde un punto de vista emics y se desarrolló una interpretación desde la perspectiva etics de los investigadores. Este proceso investigativo se adentró en el entorno socio cultural que contiene la dinámica artística de la estética popular en Cartagena, una mirada a la construcción de la publicidad popular desde las entrañas de los barrios periféricos de la ciudad. Según Aguirre Baztán: "El proceso etnográfico corresponde al trabajo de campo realizado mediante la observación participante a lo largo de un tiempo suficiente compartido con la comunidad" (cit. por Gutiérrez, 2011, p. 83). Esta etnografía buscó identificar las características culturales, conceptuales y gráficas bajo las cuales se construye este tipo de piezas publicitarias. De la misma manera se establece para esta investigación que, bajo la perspectiva de estudio cultural emics, es posible recopilar datos relevantes de forma libre y sin censuras desde la experiencia participante del investigador.

[...] Las culturas pueden estudiarse desde dos puntos de vista: uno enfocado desde la perspectiva del participante y otro desde la del observador. Los estudios enfocados desde la perspectiva del participante generan descripciones e interpretaciones emics. Los enfocados desde el punto de vista del observador generan descripciones e interpretaciones etics (Harris, 1989, p. 29). [...] Los enunciados etics, por su parte, dependen de las distinciones fenoménicas consideradas apropiadas por una comunidad de observadores científicos. Las proposiciones etics no pueden refutarse si no se ajustan a la percepción del participante de lo que es significativo, real, representativo o apropiado. Solo pueden rebatirse si se comprueba la falsedad de las pruebas empíricas aducidas por los observadores para respaldar dichas proposiciones (Harris, 1989, p. 29). 
Para esta investigación se observó, de manera participante durante tres meses, el proceso de producción que se ejecuta en el taller de José Corredor Rodelo "El Runner", uno de los exponentes más significativos en publicidad popular que posee la ciudad con su cartel picotero; se entrevistó en varias oportunidades al artista y a su grupo de colaboradores. Su punto de vista, experiencias personales y técnicas de producción alrededor del oficio, nos ofrecen un panorama que revela la esencia del fenómeno comunicativo, sus referentes creativos, procesos gráficos, distribución y dinámicas de socialización que penetran la construcción de sus piezas publicitarias. De igual manera se realizaron entrevistas a académicos que han desarrollado a lo largo de su carrera proyectos de investigación enfocados en la cultura popular.

\section{Génesis 1:1-7}

Es importante definir algunos conceptos que se mencionan a lo largo de este artículo y que han sido claves para comprender el fenómeno de la publicidad vernácula. Uno de los principales conceptos que se aborda es el de lo popular, puesto que el eje del estudio de caso se ubica específicamente en las dinámicas sociales y estéticas de dicho segmento cultural. Frente a lo popular Canclini indica "Es en esta historia lo excluido: los que no tienen patrimonio, o no logran que sea reconocido y conservado" (2001, p. 203), gracias a los estereotipos heredados y a la monopolización de la cultura por parte de la élite, lo popular se institucionalizó ante las sociedades como una categoría inferior de cultura, siendo esta una de las dinámicas más activas en la construcción creativa, rompiendo esquemas normativos y realizando composiciones funcionales, valiéndose de herramientas autóctonas. A las piezas desarrolladas bajo esta categoría se les estigmatizó como artesanías, porque eran piezas manufacturadas y empíricas. En términos de Nieves

Se prefiere pensar que se trata de formas de existencia sociocultural a veces cómplices, a veces resistentes, a veces en negociaciones complejas con lo hegemónico, esto es, acciones, representaciones, iniciativas, pasividades, que reaccionan de maneras diversas de acuerdo con las circunstancias y contextos concretos (1999, p. 9).

En ese orden de ideas, existe en la ciudad de Cartagena de Indias toda una categoría cultural que se ubica en la periferia del Corralito de Piedra, que fundamenta su comunicación y estilo de vida en el quehacer cotidiano, en la alegría Caribe, en la esencia del sabor africano y en la necesidad de subsistencia y progreso cotidianos, una hibridación revolucionaria que se expresa y vive en una rebeldía constante a la tradición elitista de la urbe, lo que se puede evidenciar en sus mensajes, en su gráfica y en los medios que utiliza para expresarse. El investigador y académico Rubén Egea, plantea:

No podemos definir en este caso a la otredad o el objeto de estudio como populares, porque este término es despectivo y te aleja del fenómeno, te aísla y es 
como si no pertenecieras a él. El término correcto para describir a estos sujetos culturales es vernáculo, haciendo referencia a constructos e imaginarios propios de un lugar (Entrevista, 2018).

Lo vernáculo es un concepto que se refiere a la identidad propia que tiene un lugar, en relación con su historia, con sus individuos y con todo lo que se ha construido alrededor del mismo, es determinado por las prácticas y usos del espacio, va en oposición directa a la globalización.

Por otro lado, se encuentra el concepto de lo publicitario como el ejercicio de hacer público o publicar información relacionada con productos o servicios tanto comerciales como sociales. En el libro "Ensayos Semióticos" el académico Vladimir Sánchez define:

La publicidad se encarga del planteamiento, diseño y ejecución de estrategias comunicativas que buscan generar en sus destinatarios una respuesta interpretativa de carácter favorable frente a un bien, servicio, producto, persona, política o ideología (...) La publicidad es un producto cultural, pues, es a partir del estudio e identificación de sistemas de significación propios de la cultura -en la que se encuentran los grupos sociales a quienes va dirigida su acción- como el publicista logra imprimir fuerza significativa a su estrategia comunicativa (Niño, 2008, p. 380).

Esta definición realiza un abordaje desde el oficio publicitario tradicional, en él se suministra una amplia mirada al ejercicio publicitario, en el cual se incluye la perspectiva cultural. En contraste con Fairchild quien define la publicidad como:

Datos puestos a disposición del conocimiento general, dados a la circulación pública. Difusión de información por medio de cualquiera de los medios de comunicación existentes [...] En las sociedades más sencillas o en los vecindarios actuales esos medios son el chismorreo, los pregones públicos etc. (1966, p. 241).

Este concepto extraído desde la perspectiva sociológica deja al descubierto la vocación comunicativa y la necesidad humanista de la publicidad al establecer como prioridad un vínculo social más allá de la imagen comercial con la cual se ha institucionalizado el término.

\section{¿Qué es publicidad vernácula?}

La publicidad vernácula parte de la asociación de dos conceptos que conforman el enunciado, de una parte publicidad referida al acto de hacer público y, vernáculo interpretado como propio del lugar. Es así como se plantea un acercamiento entre la subjetividad creativa de la publicidad y la naturalidad de la identidad popular -folk-, una validación entre las dos disciplinas que pretende rescatar las dinámicas artesanales y la estética -he- 
rramientas gráficas culturales y tradicionales con las cuales se identifican los individuos pertenecientes a una colectividad-, bajo la construcción de propuestas publicitarias que incluyan las tradiciones, la identidad y la interacción de los individuos dentro de un esquema social. En ella se invita a la publicidad a profundizar sus investigaciones con relación al público objetivo, para que sus mensajes gráficos logren una estética coherente con los identificadores culturales de la región. En pocas palabras un abordaje publicitario más completo hacia la cultura, entendida como "el modo socialmente aprendido de vida que se encuentra en las sociedades humanas y que abarca todos los aspectos de la vida social, incluidos el pensamiento y el comportamiento" (Harris, 1989, p. 17).

Sobre las contribuciones de la publicidad vernácula en el contexto cartagenero, el entrevistado Ricardo Chica (2018) señala:

Para desarrollar el concepto de publicidad vernácula hay que estudiar la sensibilidad caribeña (...) Es decir, ¿qué experiencia hemos tenido los cartageneros con la modernidad?, la modernidad entonces en Colombia en general ha consistido en lo siguiente, es una experiencia abrupta, contradictoria e inacabada, porque en Colombia hay carros pero no hay carreteras (...). Entonces uno tiene que darse cuenta que en medio de esa profunda contradicción aparecen unas lógicas que te ayudan a sobrellevar la vida y una de esas lógicas es la publicidad vernácula, una publicidad que esta marcada con la sensibilidad caribeña, ¿con qué? con los colores, con los contrastes, con la vivacidad, (...), porque la publicidad vernácula no es individualista si no que es barrial, es colectiva.

Concluyendo el autor cartagenero que básicamente es una práctica comunicativa de los sectores de la cultura popular, con la capacidad de generar sus propios códigos y convenciones a la luz de la experiencia que hemos tenido con la modernidad.

El concepto de publicidad vernácula como tal no se ha descrito académicamente, pero si se ha empleado de manera efectiva en el posicionamiento y recordación de marcas: a modo de ejemplo, en los años 90's en la ciudad de Cartagena de Indias, existió una cadena de supermercados originaria de Barranquilla, Comisariato Vivero, en ella las dinámicas publicitarias hacían referencia a las prácticas de la cultura popular, la música que ambientaba el espacio para mercar era música caribeña, alegre, de la categoría de Joe Arroyo o Diomedes Díaz. Su interés no era relajar al consumidor, por el contrario pretendía mantenerlo animado en un ambiente con el cual se identificara e incitarlo a mayor consumo de bienes, de igual manera ubicaban a un impulsador del almacén tipificado con una vestimenta tradicional de la región, pregonando con una carretilla la venta de vituallas y tubérculos, otro elemento comunicacional referido a las prácticas populares. En suma, las prácticas publicitarias al interior del supermercado Vivero - carteles promocionales, puntos de góndola e impulsadoras- hacían referencia a expresiones de la Costa Caribe, a expresiones populares. Como resultado, Comisariato Vivero aún se encuentra en la mente de los consumidores, con una percepción positiva, al punto de utilizar la marca para referirse a las nuevas cadenas ubicadas en la misma locación. 


\section{La construcción del mensaje en la Publicidad Vernácula}

La carga alegre, extrovertida y picante de la cultura Caribe, se ve reflejada en la construcción de sus mensajes publicitarios vernáculos. Su visión comercial optimista, persuasiva y aguerrida, le permite producir una estructura publicitaria empírica que mimetiza las estrategias para modificar los hábitos de consumo de la sociedad, sin perder de vista la estética que les caracteriza. $\mathrm{Al}$ respecto, conviene indicar:

Los primeros estudios realizados, sobre la norma de consumo, analizaron los objetos publicitarios como servidores de necesidades y del procesamiento informativo, es decir desde su funcionalidad. Pero recientemente se ha incorporado al análisis el concepto de gusto, que va íntimamente ligado con el de placer -hedonismo- entendido como la buena vida y el saber vivir y esto nos lleva a la relación gratificante de los objetos y las consecuencias emocionales de su uso; considerando el consumo como un proveedor de placeres (León 1995, p. 9).

Lo arriba citado, permite destacar la evolución estética en la producción de bienes simbólicos populares, existiendo una preocupación colectiva por la construcción de la identidad del producto y su proyección publicitaria, una exploración de belleza que va más allá de la funcionalidad, una búsqueda por despertar sensaciones a través de su uso. Ejemplo de ello, menciona Wilmer "Bajo" Bellido, sonidista empírico, son los equipos de sonido populares, ellos inicialmente manejaban una estética de parlantes negros, para protegerlos sus dueños solían forrar su parte frontal (llamada escaparate) con una malla de tela o fique, lo que dotaba al producto de un valor totalmente funcional; con el tiempo, ésta se convirtió en el lienzo ideal para embellecer con ilustraciones y generar valor agregado a estos monstruos del sonido (Imagen 1).

Estos equipos fueron pioneros en la creación de un tipo de identidad corporativa empíri$\mathrm{ca}$, trascendiendo en la industria del entretenimiento, que incluyen en sus presentaciones cortinillas, saludos y placas ${ }^{2}$ al inicio, durante y al finalizar las canciones, promocionando el nombre del equipo a manera de posicionamiento de marca, promoviendo artistas y productores, hasta el punto de lograr grupos sociales que se reconocen, idealizan e institucionalizan bajo la identidad de los picós. Como modelo se encuentra a los Reinaldistas, seguidores del picó Rey de Rocha, los Passa Passistas, seguidores del Passa Passa Sound Sistem, y a los Principistas seguidores de El Príncipe, entre otros.

La mimesis publicitaria desarrollada en la gráfica popular cartagenera, basa sus estrategias en los conceptos de euforia y felicidad. Según León:

La oferta de felicidad se plantea desde los anuncios publicitarios, en la búsqueda de identidad y reconocimiento por parte de los consumidores modernos, del espíritu de progreso que moviliza su sociedad [...] No importa que la realidad social sea desmotivadora, la publicidad siempre persiste en su mensaje "la vida es una sonrisa" (1995, p. 10). 


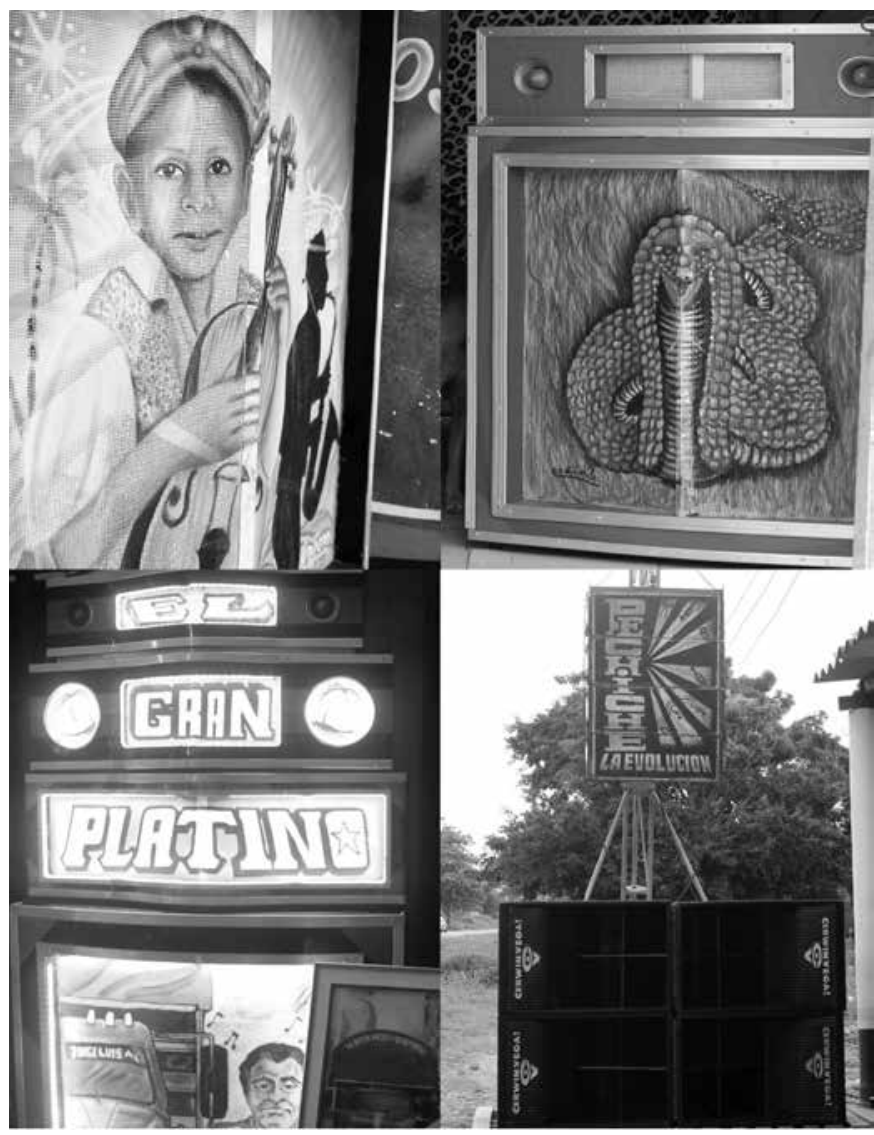

Imagen 1. Prototipos de la estética implementada en parlantes característicos de la ciudad de Cartagena de Indias.

El ideal de estas industrias de entretenimiento, es generar fuertes emociones a través de la experiencia vivencial; este proceso se gesta desde la construcción de los carteles promocionales que gracias a su manejo de color, diseño y redacción, dan inicio a la producción de sensaciones por parte de los espectadores y continúa con la puesta en escena del espectáculo sonoro, que incluye las gráficas identitarias del equipo de sonido y un desenfreno de decibeles y vibraciones que, en palabras de los nativos, producen una sensación orgásmica, puesto que aceleran las palpitaciones del corazón logrando así un estado de éxtasis en los individuos que, enardecidos, diluyen los límites que separan lo unitario de los seres y los objetos del entorno. 


\section{De vuelta al arte -boceto, trazo y pincel-}

Uno de los referentes encontrados en la visita etnográfica realizada a la ciudad de Cartagena fue el taller de José Corredor Rodelo "El Runner", un artista empírico que ha logrado junto con su equipo de trabajo "Los Runneristas" (Imagen 2) institucionalizar su estilo gráfico como uno de los principales identificadores populares de la ciudad. Lo destacado de este caso no es solo sus grafías, sino también la capacidad que ha tenido este colectivo de desarrollar todo un modelo de producción artesanal en serie que les permite producir alrededor de trescientos (300) carteles tamaño pliego en un lapso de tiempo de dos horas y media. Este proceso contempla la intervención de los carteles a partir de la experiencia de cada integrante del equipo de trabajo, es decir quien tiene más experiencia interviene el cartel con las jerarquías más importantes y quien tiene menos experticia se encarga de las líneas tipográficas de menor envergadura (Imagen 3).

En entrevista realizada a José Corredor "El Runner", menciona que sus inicios se remontan a la necesidad de agregar mejores gráficas a la producción de carteles que promocionaban los bailes picoteros en su barrio, "todo inició en el barrio, porque yo vi que los carteles estaban en blanco y negro y les faltaba color para llamar la atención, así que me ofrecí a mejorarlos a cambio de entradas a las fiestas y poco a poco se fue regando la bola de que los bailes que yo promocionaba se llenaban y que las carteleras eran vaciladas, así que cada vez más los dueños de los picós me llamaban para hacer carteleras para ellos y le tuve que decir a mi hijo "Junior" que me ayudara y poco a poco fue creciendo el taller y "el boro" de "Los Runneristas" (2018).

Este equipo de trabajo tiene procesos de preproducción, porque ellos con un lenguaje estructurado en los lineamientos culturales del entorno, se encargan de construir los mensajes de acuerdo a las necesidades de comunicación que poseen los clientes, elaboran sus bocetos que incluyen diferentes líneas de comunicación, constituidas a partir de jerarquías y proporción en la tipografía y en algunas ocasiones agregan grafismos icónicos complementarios. En producción ejecutan su modelo de manera precisa optimizando los espacios que tienen en el taller, para ubicar la mayor cantidad de pliegos y en posproducción entregan a los encargados del pegado, el material realizado. Este equipo de artistas, utiliza herramientas pedagógicas, creativas y culturales bajo las cuales asumen retos que les han permitido constituirse en referentes identitarios populares de la ciudad. Al respecto de este equipo de trabajo y su metodología, conviene indicar:

El arte suscita creatividad cuando se convierte en cultura (...) La actividad artística es, en esencia, una actividad de creación, un laboratorio de creatividad, en el que el artista identifica desafíos, busca las formas de responder a estos teniendo en cuenta su patrimonio, propone una solución e intenta legitimarla (Manito, 2011, p. 43).

Es importante reconocer que la publicidad vernácula, se vale de las bases conceptuales y técnicas del arte, edifica sus gráficas a partir de la experiencia estética de uso y la observación participante, construye códigos y lenguajes respetando la cultura, tradiciones, hábitos y estilos de vida de sus consumidores, y se toma el tiempo para desarrollar apuestas creati- 


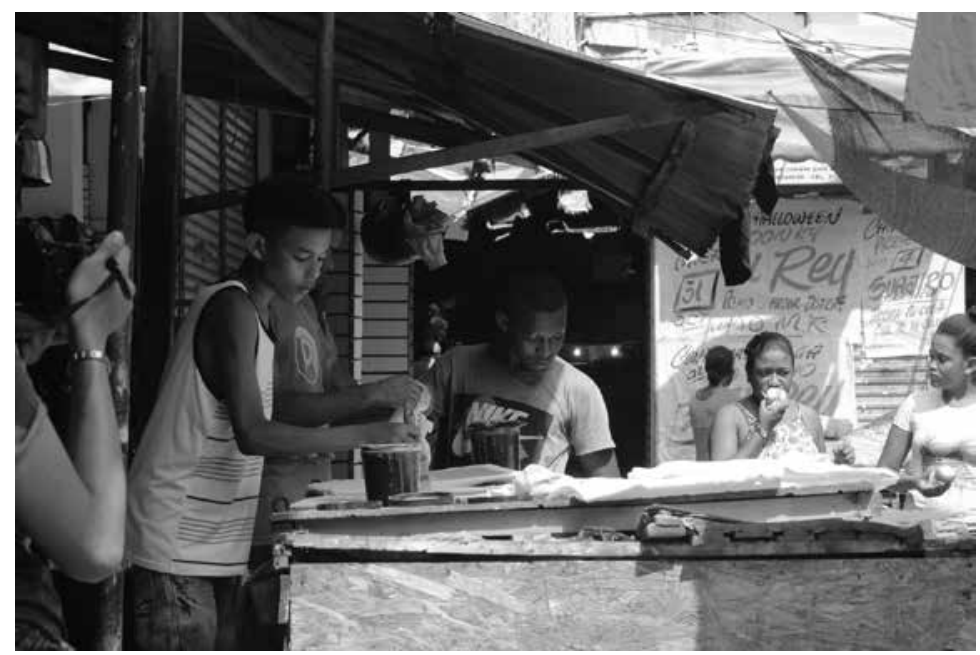

2

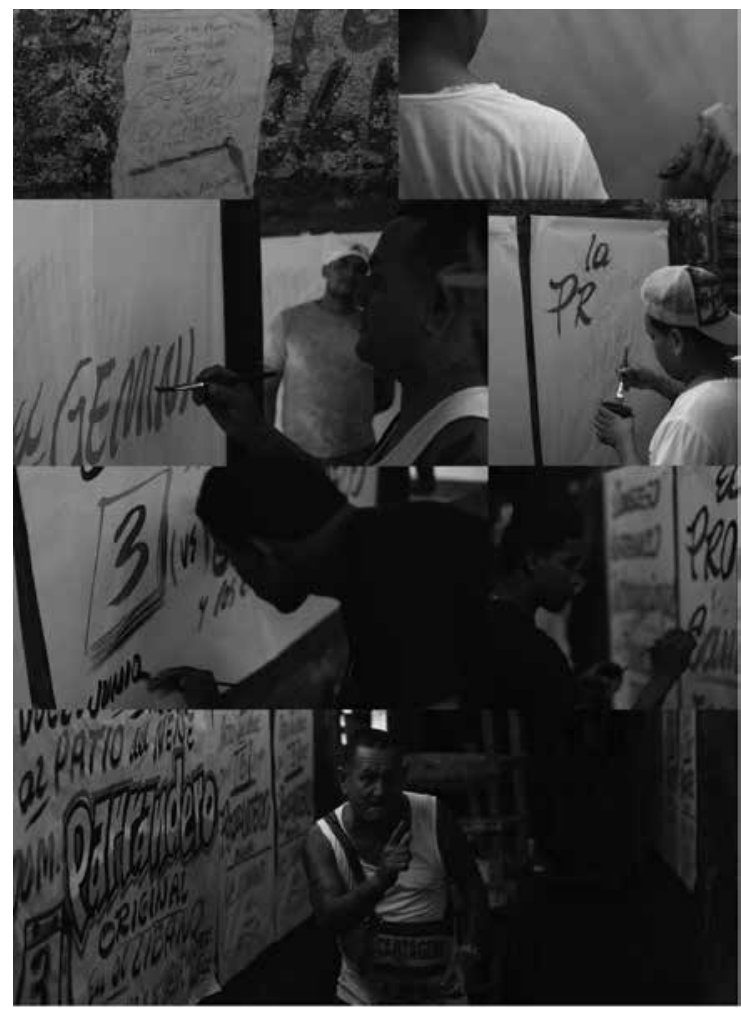

Imagen 2. "Los Runneristas", equipo de producción de carteles picoteros.

Imagen 3. Así se hace la vuelta (proceso de elaboración de carteleras). Se realiza un boceto del cartel a producir, el aprendiz agrega pegante y fija temporalmente los carteles en blanco a los muros, el "Runnerista" que esta aflojando la mano agrega un fondo amarillo al cartel, luego “El Runner” coloca las primeras pinceladas tipográficas que contienen mayor jerarquía, seguido de "El Junior" que coloca las letras que le corresponden en orden de importancia. Así sucesivamente cada "Runnerista" interviene el cartel. Por último se agregan detalles como grafismos, sombras y brillos, se espera que seque, se despega y se le entregan los carteles a los encargados de la distribución y fijación en las calles. 
vas y gráficas que representen su mensaje de manera coherente con los lineamientos gráficos identitarios propios de la comunidad a la que se dirige. Aprovecha de manera creativa su precariedad o condición en el empleo de los recursos y materiales a mano y obtiene el mayor provecho de los mismos, en su quehacer diario de aprender haciendo. Con relación a lo anterior el entrevistado Ricardo Chica comenta:

Las condiciones concretas en que se produce la publicidad vernácula se presentan de acuerdo a los recursos que tenga a su alcance el publicista popular, en donde los factores económicos dan cuenta de una precariedad de recursos que se ve representada en el uso de materiales económicos y artesanales (2018).

Gracias a esa precariedad y a la carencia de elementos modernos, la publicidad vernácula ha encontrado un vínculo de comunicación directa con su público objetivo. Desarrollar sus expresiones creativas alejado de los estereotipos y herramientas de la modernidad, le ha permitido construir un tipo de publicidad personalizada y menos global. Esbozar las ideas inicialmente en papel y finalizar sus piezas con técnicas de composición artística, le permiten conseguir en la corporeidad, el trazo y el $d u c t u s^{3}$, formas de expresión gráfica que representan y vinculan de manera emocional a los consumidores con el mensaje.

\section{Guía para el desarrollo de campañas de Publicidad Vernácula.}

Muchos son los modelos de creatividad y efectividad que utilizan las agencias publicitarias tradicionales para recopilar la información, analizarla, estructurarla e implementarla en el desarrollo de productos de comunicación. Ciertamente no existe en el ejercicio creativo y publicitario una formula mágica que permita garantizar al cliente un retorno de la inversión directamente proporcional al costo de la campaña, sin embargo un determinante clave para la efectividad y quizás la mejor manera para demostrar su respeto hacia el público objetivo es realizando una investigación rigurosa de su modo de vida, su percepción del mundo, su cultura, sus hábitos y costumbres, sus divisiones jerárquicas, su estética, manejo tipográfico y de esta manera transmitirle mensajes responsables con los cuales se identifiquen y pertenezcan. De esta manera y con todos los hallazgos realizados en una inmersión al universo creativo de "Los Runneristas", se presenta la guía para el desarrollo de campañas de Publicidad Vernácula, un compendio de los procesos que se utilizan en el taller de José Corredor Rodelo para la elaboración de carteleras promocionales de bailes picoteros.

Recopilación de la información.

1. Recepción del problema de comunicación o necesidad del cliente. ¿Cuál es el producto a pautar, descripción, beneficios, características, percepción del publico objetivo?.

2. Análisis del contexto en el cual se va a pautar el mensaje. Visite el espacio que va a intervenir, observe con detenimiento el entorno y las dinámicas sociales que allí se producen. 
3. Estudio del público objetivo, intereses, dinámicas de socialización, estilo de vida. Realice etnografías, entrevistas, notas de observación y registros audiovisuales.

4. Revisión sociológica de la comunidad a intervenir. Estudie las dinámicas de socialización que se establecen en la comunidad, cual es su estilo de vida, como perciben el mundo, como viven el día a día, que problemáticas los aquejan.

5. Escrutar la procedencia cultural de la comunidad. Es importante conocer las raíces de la comunidad, las hibridaciones culturales posibles, sus herencias estéticas y cromáticas.

6. Análisis de los hábitos, costumbres y tradiciones del público objetivo. Esto le permitirá crear estrategias de interacción asertivas con la comunidad. Usted sabrá cuándo, dónde y cómo se desarrollan las dinámicas de socialización.

7. Auscultar las dinámicas estéticas con las cuales se establece la comunicación al interior de la comunidad -color, tipografía, espacios intervenidos-. Conocerá el lenguaje que se maneja al interior de la sociedad y los códigos de comunicación con los cuales se identifican. 8. Análisis de los códigos y lenguajes utilizados por la colectividad. Centre su atención de manera específica en este punto, pues es la clave para conectar con su público objetivo.

9. Estudiar las rutas de movilidad de la comunidad, principales puntos de convergencia laborales, culturales y rituales-. Si usted conoce dónde se ubican y por qué lugares se movilizan los individuos de esa comunidad, su mensaje estará en los espacios de convergencia y en el campo visual correcto para generar impacto y recordación.

10. Revisar los principales medios de consumo de la comunidad. Para que el receptor se sienta a gusto y receptivo con el mensaje, se debe estudiar que tipo de medios son los utilizados y reconocidos para pautar. No son los medios de mayor difusión los más funcionales, son los medios y espacios con los cuales se identifica su público objetivo.

Preproducción.

1. Formalización de la información. Estructure en un brief toda la información y análisis recopilados.

2. Construcción de concepto e idea. Es importante que sepa que va a comunicar, para luego establecer como lo quiere comunicar, de acuerdo a la estructura de brief elaborada.

3. Construcción del mensaje, códigos y lenguaje a utilizar. Una vez sepa que va a comunicar, desarrolle su mensaje utilizando los códigos y lenguaje con los que se interrelaciona la comunidad.

4. Creación de la paleta de color de acuerdo al análisis y descripción del público objetivo. Solo manejando los lineamientos estéticos del entorno logrará el reconocimiento e identidad de la comunidad y con ello el impacto visual y la comunicación asertiva de su mensaje.

5. Creación de bocetos tipográficos de acuerdo al análisis y descripción del público objetivo.

6. Creación de una retícula o estructura de diagramación acorde con los lineamientos estéticos de la comunidad a intervenir.

7. Diseño de bocetos con herramientas artísticas. Se debe tener en cuenta la precariedad de los materiales y el entorno en el cual convive el público objetivo, para generar una identidad, reconocimiento y sentido de pertenencia por parte de la comunidad hacia su mensaje. 


\section{Producción}

1. Lidere el proceso de producción, distribuyendo las funciones de los operarios de acuerdo a sus competencias técnicas y experiencia. Confíe en su equipo de trabajo, instrúyalo de manera periódica y delegue responsabilidades para que sus proyectos no dependan única y exclusivamente de su presencia y calidad técnica.

2. Elabore las piezas teniendo en cuenta los resultados del análisis de la comunidad, códigos estéticos, culturales, tradiciones, lenguaje, tenga en cuenta los materiales y medios que utiliza la comunidad para comunicarse.

3. Utilice la expresión artística como herramienta de solución gráfica primordial. Esto le permite generar mensajes alejados de lo global, personalizar y penetrar los intereses del público objetivo.

4. Desarrolle una gráfica que contenga los elementos estéticos con los cuales se identifica la comunidad, paleta de color, tipografía, trazo, sustrato, etc.

5. Construya una línea de producción funcional, que permita disminuir los tiempos de producción.

Medios.

1. Paute las piezas publicitarias de acuerdo a las dinámicas de movilidad de la colectividad.

2. En lo posible utilice medios vernáculos, perifoneo, carteles, murales, con ellos el público se sentirá a gusto y recibirá la información de manera más abierta y receptiva.

3. Construya nuevos medios y espacios de pauta de acuerdo a las dinámicas de socialización del grupo social.

4. Respete las reglas de comunicación urbana que existan en la comunidad, delimitación de territorios, competencia gráfica, jerarquías y sistemas de comunicación preestablecidos en la comunidad.

\section{Conclusiones sobre la Publicidad Vernácula}

Tiene la propiedad de reinventarse de manera periódica, busca alternativas de solución a sus problemas de comunicación, amplia sus horizontes y medios en la medida de sus necesidades; con pertinencia de lo expresado por Manito sobre la creatividad: "Tiene la capacidad de romper convenciones, las ideas 'hechas', para permitir la emergencia de visiones, ideas o productos nuevos" (2011, p. 43). Por ejemplo: el cartel picotero encontró hace varios años un medio de publicación en el muro de la antigua fábrica de hielo Imperial y construyó un tipo específico de gráfica, con mayor impacto que el cartel de pared y poste, tipografías rotuladas de mayor jerarquía y grosor y mensajes más cortos que lograban mejor lecturabilidad en los receptores, teniendo en cuenta que este espacio era el de mayor circulación de su público objetivo -el muro de la fábrica de hielo se encontraba en la principal vía de acceso al mercado Bazurto-, transeúntes y automotores de servicio público. En el año 2010, gracias a la modernización -construcción de las vías para el tramo 5B del sistema integrado de transporte Transcaribe- el muro se demolió y con él, lo que era considerado el principal medio de difusión del cartel picotero. En esa coyuntura, la pu- 
blicidad vernácula desarrolló un nuevo medio de difusión, los murales picoteros, para lo cual tuvo que aprender y emplear nuevas técnicas de lenguaje urbano -uso de aerosoles y expresiones del tipo grafiti-, que lograron causar mayor impacto en su público objetivo, sin alejarse de su estética diferencial e identitaria.

Desarrolla un análisis experiencial de su público objetivo y de las dinámicas sociales que se producen al interior de las comunidades a las que se dirige. En el trabajo de campo se observó y analizó el manejo cromático para diferentes regiones -Cartagena y Barranquilla- de acuerdo a sus configuraciones y codificaciones culturales, para la primera ciudad se emplean colores vivos y primarios sobre lienzos blancos con fondo amarillo, para La Arenosa se maneja una paleta cromática más excéntrica, fondos negros con colores primarios y fluorescentes, como quiera que tiene en cuenta el manejo cromático y la estética de los carnavales barranquilleros. Analiza los espacios con mayor afluencia de personas, por ejemplo las principales vías de tránsito de la ciudad, los espacios más concurridos en barrios, plazas de mercado, lugares de ocio, de congregación por ritualización, costumbres y tradiciones -cementerios, colegios, iglesias entre otros-.

Construye sus propios códigos y lenguajes a partir de los resultados de sus intervenciones en las comunidades y la búsqueda de elementos identitarios de los mismos. Sabe realmente a quién, cómo, cuándo y dónde dirigirse. Maneja un lenguaje y códigos gráficos explícitos con los cuales se identifican los receptores, construyendo un vínculo de recordación e identidad. Sus mensajes son alegres, positivos y su lenguaje popular. Sin alejarse de la realidad que rodea a sus consumidores, utiliza adjetivos calificativos para incrementar el interés en sus mensajes -el popular Mr. Black, el gran Rey de Rocha, el poderoso Guajiro, entre otros- y avala los eventos con su promoción, de ahí que José Corredor dictamine "un baile que no es promocionado con carteles de El Runner se poncha” (2018).

Diseña sus modelos de fabricación bajo una cadena de producción preestablecida, en donde las responsabilidades se distribuyen de acuerdo a la experiencia de los operarios. Delega funciones específicas de acuerdo a las competencias técnicas adquiridas por los aprendices. Posee una línea de jerarquías tipo organigrama. Para el caso del cartel picotero, el líder es Runner -30 años de experiencia aproximadamente-, luego sigue José Jr. -15 años de experiencia-, 8 operarios -entre 2 y 4 años de experiencia- y dos aprendices -con 3 meses de experiencia-.

La publicidad vernácula es pedagógica, permite a sus operarios incrementar sus conocimientos. Los hallazgos obtenidos en la experiencia del quehacer diario se transmiten sin restricciones a los aprendices y su crecimiento gráfico incrementa sus jerarquías dentro del sistema de producción. El taller de José Corredor Rodelo es una especie de escuela de arte en donde día a día los aprendices desarrollan su capacidad gráfica, imitando el ductus de Runner. Es un espacio abierto a la creatividad, aspecto que se percibe al observar los muros en donde los aprendices practican de manera libre sus trazos tipográficos, antes de intervenir los carteles.

La creatividad artística contenida en la publicidad vernácula es clave para el desarrollo de la cultura. Señala Manito (2011, p. 43): "Las artes todavía son pertinentes, puesto que la creatividad artística pone al día tanto una cultura de proyecto, como una cultura técnica o una cultura de la comunicación". Es decir, al defender los valores culturales, tradicionales y sociales de una comunidad, al entender cuales son sus gustos, preferencias y formas de 
entender el mundo, se logra obtener un significado de lo que es el público objetivo, el contexto en el que convive y como se puede proyectar su identidad a través de los mensajes, de esta manera se construye un modelo publicitario que se define como una cultura de la comunicación, descrita por sus receptores como la gráfica picotera con la cual se identifica el sector popular de la ciudad.

\section{Notas}

1. El origen divino del universo vernáculo.

2. Formatos comerciales populares de audio, propios de las producciones de champeta que impulsan artistas, personajes, situaciones y el mismo producto, bajo una estética ecoica.

3. Cualidades y características propias del trazado artístico para la construcción de composiciones tipográficas caligráficas que se perfeccionan a través del tiempo, con la práctica continua y la experiencia del creativo.

\section{Bibliografía}

Amossy, R. y Herschberg, A. (2001). Estereotipos y clichés. Enciclopedia semiótica. Buenos Aires: Argentina Editorial Eudeba.

Ewen, S. (1991).Todas las imágenes del consumismo: la política del estilo en la cultura contemporánea. Cap. III. El matrimonio entre el arte y el comercio. Grijalbo.

Douglas, N. (2008). Ensayos Semióticos. Fundación Universidad de Bogotá Jorge Tadeo Lozano 2008.

Fairchild, H. (1966). Diccionario de sociología. México: Fondo de cultura económica.

Figueroa, C. (2005). Memoria y ciudades en la narrativa colombiana contemporánea. El caso de Cartagena de Indias. Artículo de reflexión. Colombia: Pontificia Universidad Javeriana, Universidad Colegio Mayor de Cundinamarca.

Gadamer, H.(1991). La actualidad de lo bello: el arte como juego, símbolo y fiesta. Paidós Ibérica.

García Canclini, N. (2001). Culturas híbridas: estrategias para entrar y salir de la modernidad. México: Paidós.

García Usta, J. (2002). Cultura y competitividad: ¿Cómo reforzar la identidad caribe de Cartagena? Cartagena de Indias: Alcaldía Mayor de Cartagena de Indias-Instituto de Patrimonio y Cultura de Cartagena.

Gutiérrez, J. A. (2011). Proceso de la investigación cualitativa Epistemología, metodología y aplicaciones. Colombia: Editorial El Manual Moderno.

Harris, M. (1989). Teorías sobre la cultura en la era posmoderna. Barcelona: Crítica.

León, J. (1995). Los efectos estéticos de la publicidad. Questiones publicitarias: revista internacional de comunicación y publicidad, ISSN 1133-6870, №. 4, 1995. 9-26. 
Maffesoli, M. (2004) La transfiguración de lo político. La tribalización del mundo posmoderno. México: Herder Editorial.

Manito, F. (2011). Ciudades creativas. Barcelona: Ediciones Bellaterra.

Muñoz, F. (2008). Urbanalización. Paisajes comunes, lugares globales. Barcelona: Editorial Gustavo Gili, SL.

Nietzsche, F. (1980). El nacimiento de la tragedia. España: Alianza.

Nieves, J. (1999). Vislumbres del caribe: iconografías y textualidades híbridas en Cartagena de Indias. Observatorio del Caribe Colombiano, Universidad de Cartagena (1999).

Posso, L. (2013). "Regeneración urbana, valor cultural e inclusión social. El caso del barrio Getsemaní, Cartagena de Indias”. Investigación para obtener el título de Master Oficial en Gestión Cultura, Itinerario Investigación, Universidad de Barcelona.

Posso, L. (2014). "Getsemaní, Casa Tomada”. Análisis del desplazamiento poblacional en el histórico barrio cartagenero. Libro ganador de la I Convocatoria de Estímulos a la creación artística de ICULTUR.

Sandoval, C. (1996). Investigación cualitativa. Programa de especialización en Teoría, métodos y técnicas de investigación social. ICFES Colombia (1996).

Pérez, S.(2004). PASOS. Revista de Turismo y Patrimonio Cultural [en linea] 2004, Disponible en: $<$ http://www.redalyc.org/articulo.oa?id=88120113 > ISSN 1695-7121

Horkheimer, M. y Adorno, Th. W. (1971). Dialéctica del iluminismo. Buenos Aires: Editorial Sur.

Polanco, J. (2013). Coloquio en investigación maestría en publicidad. Universidad Jorge Tadeo Lozano. Bogotá, Colombia.

\begin{abstract}
This article is the result of research entitled "Vernacular Advertising, Phase I. Analysis of the media and models of popular advertising production", which ended in 2019 with resources from the Jorge Tadeo Lozano University. The purpose of this text is to give an account of the identity points that are built in the peripheral spaces of Cartagena de Indias, that is, those communication tools used by merchants, artists and artisans to solve their dissemination and product promotion needs or services in the daily marketing dynamics that they execute. To account for this phenomenon, the Urban Languages hotbed was given the task of carrying out a bibliographic review process to document the main concepts addressed in the exercise of popular advertising production -Vernacular advertising-conducted in-depth interviews. Structured academics and empirical artists to locate processes, spaces and media where vernacular advertising is involved, participated in the production workshops of José Corredor Rodelo "El Runner" as an ethnography and made tours to document when, how, where and why This type of advertising is used.
\end{abstract}

Keywords: culture - popular - urban - vernacular - advertising - society - language - communication - design and image. 
Resumo: Este artigo é fruto da pesquisa "Publicidade vernacular, fase I. Análise da mídia e modelos de produção publicitária popular", que terminou em 2019 com financiamento da Universidade Jorge Tadeo Lozano. O objetivo deste texto é dar conta dos pontos identitários que se constroem nos espaços periféricos de Cartagena das Índias, daquelas ferramentas de comunicação utilizadas por comerciantes, artistas e artesãos para solucionar suas necessidades de divulgação e promoção de produtos ou serviços. .na dinâmica de marketing do dia-a-dia que administram. Para registrar esse fenômeno, o viveiro de Linguagens Urbanas empreendeu a tarefa de realizar um processo de revisão bibliográfica, documentando os principais conceitos que são abordados no exercício da produção publicitária popular -Publicidade vernacular-, conduzindo entrevistas não estruturadas em profundidade com acadêmicos e empíricos. artistas para localizar processos, espaços e mídias onde a publicidade vernacular intervém, participaram das oficinas de produção de José Corredor Rodelo "El Runner", utilizando técnicas etnográficas, e realizaram tours para documentar quando, como, onde e por que se utilizou este tipo de Anúncio.

Palavras chave: Cultura - popular - urbano - vernáculo - publicidade - sociedade - linguagem - comunicação - design e imagem.

[Las traducciones de los abstracts fueron supervisadas por el autor de cada artículo] 